Revista de Derecho

de la Pontificia Universidad Católica de Valparaíso

XXXII (Valparaíso, Chile, $1^{\text {er }}$ Semestre de 2009)

[pp. 107 - 132]

\title{
ESTRUCTURA Y JURISDICCIÓN DE LAS ORGANIZACIONES DE USUARIOS DE AGUAS EN CHILE DURANTE EL SIGLO XIX
}

["Structure and Jurisdiction of Organizations of Water Users in Chile During the 19th Century"]

\author{
Iván Mauricio Obando Camino* \\ Universidad de Talca, Chile
}

\begin{abstract}
RESUMEN
Abstract

Este artículo analiza las organizaciones de usuarios de aguas en Chile antes de la emisión de la Ley $\mathrm{N}^{\circ} 2.139$, de 1908, para determinar cuáles fueron las formas asociativas empleadas por los regantes para organizarse hasta aquel entonces y si estos últimos confirieron atribuciones jurisdiccionales a dichas organizaciones para resolver los conflictos derivados del ejercicio de los derechos de sus asociados.

Esta investigación verifica el empleo de instituciones jurídicas novedosas, originadas en figuras contractuales y cuasicontractuales, que dieron lugar

This article analyzes the water users associations that existed in Chile before the enactment of the 1908 Act No 2139. This analysis pursues to determine the type of associations used by water users up till then and whether or not they conferred upon those associations a judiciary authority to deal with conflicts about the exercise of water users' rights.

This research verifies the use of novel legal institutions, based both on contracts and quasi- contracts, which gave way to an organizational model that sprung out of some common features. Likewise, this research establishes the existence of, at

* Licenciado en Ciencias Jurídicas por la Universidad Católica de Valparaíso, M. A. y Ph. D. en Ciencia Política por la Universidad Estatal de Nueva York en Albany. Profesor Asistente de Derecho Público, de Minas y de Aguas de la Facultad de Ciencias Jurídicas y Sociales de la Universidad de Talca. Dirección postal: Facultad de Ciencias Jurídicas y Sociales, Universidad de Talca, Avda. Lircay s/n, Talca, Chile. Correo electrónico: iobandoc@utalca.cl El autor agradece los gentiles comentarios del profesor Dr. Rodrigo Barcia Lehmann. Los errores u omisiones son de exclusiva responsabilidad del autor. En los textos citados se ha conservado la ortografía antigua con que fueron impresos los originales.
\end{abstract}


a un modelo organizativo basado en ciertas notas comunes. Asimismo, la investigación establece la existencia de cinco opciones de diseño institucional, a lo menos, entre 1831 y 1908 , respecto del otorgamiento de atribuciones jurisdiccionales a organizaciones de usuarios de aguas.

Palabras clave: Organización de usuarios de aguas - Jurisdicción - Derecho de Aguas. least, five alternative institutional designs that dealt with the granting of judiciary authority to water users associations from 1831 through 1908.

KEY wORDS: Water users associations - Jurisdiction - Water Law.

\section{INTRODUCCIÓN}

1. Este artículo analiza las organizaciones de usuarios de aguas existentes antes de la emisión de la Ley $\mathrm{N}^{\circ}$ 2.139, de 1908, que reguló las asociaciones de canalistas, con el objeto de determinar cuáles fueron las formas asociativas empleadas concretamente por los regantes para organizarse jurídicamente y si dichas organizaciones tenían atribuciones jurisdiccionales para resolver reclamaciones o conflictos relativos al ejercicio de los derechos de sus asociados. La respuesta a estas interrogantes permite precisar, mediante el análisis de la evidencia documental, los comentarios generales de la doctrina en la materia y complementar hallazgos previos del autor sobre el origen de la jurisdicción arbitral en el derecho de aguas chileno, proporcionado así una visión más acabada sobre el repertorio organizacional e instituciones empleadas por los usuarios de aguas antes de 1908.

Para estos efectos, este artículo pasa revista a las formas asociativas empleadas para la distribución de las aguas antes de 1908, lo que permite constatar el empleo instrumental de instituciones jurídicas tradicionales, dada la inexistencia de un cuerpo legal que regulara especialmente la organización y funcionamiento de las organizaciones de usuarios de aguas. Esta constatación, a su turno, permite identificar ciertas notas comunes a todas las organizaciones de usuarios de aguas, las que en su conjunto sugieren la existencia de un modelo organizativo distintivo, el que atravesaba las diversas formas asociativas estudiadas.

Acto seguido, este estudio analiza si los usuarios de aguas confirieron atribuciones jurisdiccionales a las organizaciones jurídicas creadas por ellos, con el objeto de resolver reclamaciones o conflictos relativos al ejercicio de los derechos de sus asociados. Este análisis revela que varias de estas organizaciones otorgaron atribuciones jurisdiccionales a sus órganos ad- 
ministrativos, con el objeto de resolver tales reclamaciones o conflictos, empleando para ello diversas instituciones jurídicas. Este estudio pone de manifiesto la existencia de cinco opciones de diseńo institucional, a lo menos, para efectos del otorgamiento de estas atribuciones jurisdiccionales, entre los años 1831 a 1908. Lo anterior proporciona una visión general de las diversas opciones de diseño institucional que existían en esta materia hacia principios del siglo XX.

2. Este estudio constituye una investigación jurídica dogmática de carácter histórico, la que emplea fuentes documentales para responder el par de interrogantes formuladas arriba, describiendo de paso la regulación de un fenómeno asociativo que existió en el derecho de aguas decimonónico chileno. Los métodos empleados son el histórico y el analítico.

Las fuentes documentales empleadas para esta investigación son los comentarios de autores, la legislación nacional, los estatutos o reglamentos de organizaciones de usuarios de aguas decimonónicas disponibles en bibliotecas nacionales y la jurisprudencia judicial. La primera consiste en los comentarios de autores del derecho de aguas o derecho agrario, excluyéndose los comentarios de memoristas de prueba en derecho. La segunda dice relación con la legislación de derecho común y de regadío vigente antes de 1908. Esta legislación fue compilada por particulares, nacionales y extranjeros. La tercera consiste fundamentalmente en aquellos estatutos o reglamentos aprobados antes de 1908 y que se encuentran disponibles para su consulta en bibliotecas y archivos, tanto públicos como universitarios. En la especie, éstos se reducen a ocho estatutos o reglamentos, todos ellos disponibles en la Biblioteca Nacional ${ }^{1}$. Adicionalmente, fue posible obtener copia del reglamento de otra organización de usuarios de aguas en archivos notariales, gracias a referencias encontradas en estatutos posteriores ubicados en la Biblioteca Nacional ${ }^{2}$. Todos los estatutos o reglamentos

${ }^{1}$ La búsqueda de estatutos o reglamentos se realizó en las siguientes bibliotecas y archivos: Biblioteca del Congreso Nacional, Archivo Nacional, Biblioteca Nacional, Catálogo Bello de la Universidad de Chile, Sistema de Bibliotecas UC (SIBUC) de la Pontificia Universidad Católica de Chile, Biblioteca Central de la Universidad de Talca y bibliotecas públicas dependientes de la DIBAM. Los estatutos o reglamentos encontrados fueron los relativos a las siguientes comunidades y sociedades: Canal de Maipo, Canal de Ochagavía, Canal de Las Perdices, Canal Pinto-Solar, Canal de La Pampa, Canal de La Cañada (Curicó), Canal de La Herradura y Canal de la Calera de Tango. Existen referencias a otras comunidades y sociedades de canalistas y regantes decimonónicas en la discusión de la ley sobre asociaciones de canalistas en el Senado, pero sus estatutos y reglamentos no pudieron ser ubicados en las bibliotecas y archivos antes mencionados: Canal de La Pólvora, Canal Caupolicán, Canal de Las Mercedes, Canal del Carmen, Canal Nuble y Canal Cato.

${ }^{2}$ Se trata del Reglamento de la Sociedad de los Canales de Yungay y Zapata, en- 
encontrados presentan ciertas notas comunes, las que permiten determinar la existencia de un fenómeno jurídico distintivo en el derecho de aguas decimonónico chileno como objeto de estudio. La cuarta la constituyen las sentencias judiciales publicadas en las principales revistas de jurisprudencia de la época, v. gr. la Gaceta de los Tribunales y la Revista de Derecho y Jurisprudencia, bajo sus diversas denominaciones.

3. Este artículo consta de cuatro secciones, incluidas la Introducción y las Conclusiones. La sección I. analiza las formas asociativas empleadas por los usuarios de aguas en Chile, antes de la emisión de la Ley N².139, de 1908. La sección II. se refiere a la jurisdicción conferida a las organizaciones de usuarios de aguas, con respecto a sus integrantes, a la luz de los mismos estatutos o reglamentos, deteniéndose especialmente en sus aspectos organizacionales.

\section{FORMAS ASOCIATIVAS EMPLEADAS POR LOS USUARIOS DE AGUAS ANTES DE 1908}

I. El derecho de aguas decimonónico no contó con un estatuto jurídico especial que regulara la constitución y funcionamiento de las organizaciones de usuarios de aguas. Estas últimas sólo fueron reguladas mediante la Ley $\mathrm{N}^{\circ} 2.139$, de 1908, la que reglamentó la organización y funcionamiento de las diversas comunidades y asociaciones de regantes y canalistas que habían surgido en décadas previas. Muchas de estas comunidades y asociaciones funcionaban sin sujetarse a norma jurídica alguna, sino simplemente de hecho.

Así lo reconoció Lastarria en 1875, cuando propuso legislar sobre la materia al Congreso Nacional. Lastarria sostuvo que estos fenómenos sociales funcionaban de hecho y que sus peculiaridades desaconsejaban el empleo del cuasicontrato de comunidad para su regulación. En tal sentido, él afirmó que: "[c]asi todos los aprovechamientos colectivos de aguas públicas existen hoy de hecho entre comuneros, que no tienen regla alguna para su goce; pues las sociedades constituidas i rejimentadas son mui pocas. Es cierto que el cuasicontrato de comunidad está legislado en el Lib. IV, tít. XXXIV, $\$ 3 .^{\circ}$ del Código Civil, pero es de una manera jenérica, que no se aplica jamas a las numerosas comunidades de regantes que existen $i$ que se usan i ventilan sus derechos arbitrariamente $i$ sin lei alguna [...]"3. En el mismo sentido

contrado en los registros notariales de Santiago, en el Archivo Nacional. En los registros notariales de Ovalle, presentes también en el Archivo Nacional, fue encontrado el contrato que dio origen a lo que fue conocido posteriormente como la Asociación de Canalistas del Canal de Camarico.

${ }^{3}$ Lastarria, José Victorino, Proyecto de Código Rural para la República de Chile: 
concurrió Venegas en 1887, quien señaló en su recopilación de legislación sobre regadío que: "[p]ocos son los canales que, como el de Maipo, se rijen bajo ciertos estatutos especiales; en la mayor parte de los canales no impera regla alguna para su uso, como quiera que el párrafo del Código Civil que trata del cuasi contrato de comunidad se limita a consignar preceptos jenerales que no pueden aplicarse a las diversas situaciones que presenta el derecho de usar una mismas aguas numerosos predios de reducida estension" ". No obstante, algunas comunidades y asociaciones fueron capaces de organizarse jurídicamente e inclusive de obtener reconocimiento por la autoridad pública.

Efectivamente, los usuarios de aguas se vieron forzados a organizarse jurídicamente, como consecuencia del hecho que utilizaban los mismos cauces para conducir las aguas y ello generaba diversos conflictos jurídicos 5 . Para ello adaptaron a sus necesidades organizativas las instituciones jurídicas autorizadas por el derecho vigente ${ }^{6}$. No obstante la opinión en contrario de Venegas, diversos autores señalan que la asociación de hecho que surgía entre los usuarios de aguas era organizada a través del cuasicontrato de comunidad, para lo cual algunas comunidades llegaban incluso a darse estatutos o reglamentos ${ }^{7}$. El reconocimiento de la autoridad pública, a

acompañado de un apéndice con notas ilustrativas (Santiago, Imprenta de la República, 1875), pp. 149-150.

${ }^{4}$ Venegas, Fortunato, Legislacion Chilena sobre Aguas de Regadio (Santiago, Imprenta Gutenberg, 1887), p. 102.

${ }^{5}$ Ibíd.; Lira Urquieta, Pedro - De la Maza, Lorenzo, Régimen legal de las aguas (Santiago, Editorial Nascimento, 1940), p. 102; Lira Ovalle, Samuel, El Derecho de Aguas ante la cátedra (Santiago, Universidad Católica de Chile, Facultad de Ciencias Jurídicas, Políticas y Sociales, 1956), p. 155; SEDA, Mario, Las Juntas de Vigilancia en el Código de Aguas, en Hederra, Ana - Vergara, Ciro, Comentarios al Código de Aguas (Santiago, Editorial Jurídica de Chile, 1960), II, p. 3; Guzmán, Alberto - Ravera, Ernesto, Estudio de las Aguas (2a edición, Santiago, Ediciones Congreso, 1998), p. 133.

${ }^{6}$ Este trabajo de adaptación jurídica no se limitó sólo a la constitución y funcionamiento de sus organizaciones, sino que se extendió también a otros aspectos, como el derecho de garantías, en el que existió una prenda de derecho común, sin desplazamiento, sobre regadores de agua. OBando, Iván M., La prenda especial de derechos de aguas: Antecedentes sobre derechos de aguas y contratos de garantía en perspectiva histórica (1855-1981), en Revista de Derecho de la Pontificia Universidad Católica de Valparaiso 26 (2005) 2, p. 263.

${ }^{7}$ Lira, Pedro - De la Maza, Lorenzo, cit. (n. 5); Lira, Samuel, cit. (n. 5), pp. 155 s.; Merino, Ernesto, Las comunidades de aguas, en Hederra, Ana - Vergara, Ciro, cit. (n. 5), I, pp. 449, 454; Seda, Mario, cit. (n. 5), pp. 3 s.; Stewart, Daniel, El Derecho de Aguas en Chile: Algunos aspectos de su historia y el caso del Valle de Illapel (Santiago, Editorial Jurídica de Chile, 1970), p. 104; FigueroA, Luis S., Asignación $y$ distribución de aguas terrestres (2a edición, Santiago, Universidad Gabriela Mistral, 1997), p. 90; Guzmán, Alberto - Ravera, Ernesto, cit. (n. 5), pp. 133 s. 
su turno, se obtenía sometiendo los estatutos o reglamentos respectivos, cuando se contaba con ellos, a la aprobación del Poder Ejecutivo en virtud de las normas generales de gobierno interior y policía administrativa, $v$. gr., al Presidente de la República o Intendente provincial. Huelga decir que aquellas comunidades que carecían de estatutos o reglamentos no podían aspirar a dicho reconocimiento. En otros casos, dichos estatutos o reglamentos eran acordados previamente en sede judicial, lo que les otorgaba reconocimiento por una autoridad pública. La existencia de este fenómeno jurídico, reconocido o no por la autoridad pública, sus consecuencias jurídicas para la distribución de las aguas y el debate concerniente a su juridicidad, condujeron a la emisión de la Ley No 2.139, la que facultó a los integrantes de tales comunidades y asociaciones para modificar los estatutos o reglamentos existentes, u otorgarlos por primera vez, de acuerdo con las nuevas prescripciones legales.

Sin embargo, el estudio de los estatutos o reglamentos de organizaciones de usuarios de aguas disponibles en bibliotecas y archivos nacionales revela que el repertorio organizacional de los usuarios de aguas no se limitaba solamente al citado cuasicontrato, pues también empleaban figuras contractuales para fines organizacionales, como el contrato de sociedad.

2. Este es el caso de la primera organización de usuarios de aguas que existió en el Chile republicano. Nos referimos a la Sociedad del Canal de Maipo, cuya constitución fue posible gracias a un sofisticado trabajo de adaptación jurídica, ya que sus integrantes se organizaron "en compañia" para fines de la administración y terminación del Canal San Carlos de Maipo, una vez que el gobierno transfirió la propiedad del mismo a los propietarios de los regadores de agua en mayo de 1827. Con este objeto en mente, ellos celebraron una sesión constitutiva el 5 de julio de 1827, en Santiago, en que acordaron su instrumento constitutivo, el Acta de Asociación de los Propietarios del Canal de Maipo ${ }^{8}$. Esta acta señaló en su artículo $1^{\circ}$ que: "[1]os propietarios del agua del Canal de San Cárlos, se reunen en compañia con el objeto de disfrutarlo i conservarlo, proveyendo a cuanto fuese necesario para ello con igualdad i proporcion a sus acciones". Huelga indicar

\footnotetext{
${ }^{8}$ Sociedad del Canal de Maipo, Direccion del Canal de Maipo 1827-1856 (Santiago, Imprenta Gutenberg, 1886), pp. 8 s.

${ }^{9} \mathrm{El}$ instrumento notarial original, según edición facsimilar tenida a la vista, tenía por título "Proyecto de Asociacion presentado á la Junta general el 5 de Julio de 1827"; y contiene un proemio en que se alude al "pacto de su union" y a la "compañia." Dicho instrumento, una vez firmado por los accionistas, fue transcrito en los diversos documentos de la sociedad llevando por título: "Acta de Asociacion de los Propietarios del Canal de Maipo", y se lo conoció así en lo sucesivo. Sociedad del Canal De MaIpo, Canal San Carlos: orígenes e influencia en la ciudad de Santiago (Santiago,
} 
que esta forma de organización social no tenía parangón en el derecho vigente. Las compañías, reguladas en las Siete Partidas, de Alfonso X, se basaban en las sociedades del derecho romano y carecían de personalidad jurídica, mientras que las Ordenanzas de Bilbao contemplaban las compañías de comercio, que correspondían a sociedades mercantiles de personas; sin embargo, la naturaleza y objetivos de unas y otras no correspondían exactamente a los de la compañía formada por los accionistas del Canal de Maipo, máxime si ellos no aportaban sus regadores de agua para constituir un fondo social. Esta originalidad de los fundadores de la compañía, consistente en emplear instrumentalmente las normas jurídicas vigentes, fue hecha notar por la misma compañía años más tarde, cuando enfatizó que su nacimiento, en difíciles circunstancias materiales, constituyó "[...] en Chile el primer ensayo de lo que puede el espiritu de asociacion. [...]"10. El Presidente de la República aprobó los estatutos respectivos mediante el Decreto de 3 de marzo de 1832, del Ministerio de Interior y Relaciones Exteriores, publicado en El Araucano $\mathrm{N}^{\circ} 79$. Años más tarde, la Corte Suprema reconoció a esta sociedad como persona jurídica, no obstante la peculiaridad de su objeto y el haber sido constituida casi tres décadas antes de la entrada en vigencia del Código de Bello, como lo recordó el Ejecutivo en la exposición de motivos del proyecto de ley sobre asociaciones de canalistas, remitido al Congreso Nacional en $1907^{11}$.

3. Muchas de las organizaciones de usuarios de aguas que surgieron en años posteriores lo hicieron bajo la forma de un cuasicontrato de comunidad. ${ }^{12} \mathrm{El}$ antiguo artículo $836 \mathrm{CCCh}$. daba pie para ello, porque preceptuaba que: "[e]l uso de las aguas que corren por entre dos heredades corresponde en comun a los dos riberanos, con las mismas limitaciones, i será reglado en caso de disputa por la autoridad competente, tomándose en consideración los derechos adquiridos por prescripcion u otro título, como en el caso del artículo precedente, núm. 1. "'. Para estos efectos, los juicios de aguas se sujetaron a diversos cuerpos legales en el tiempo, tales como el Reglamento de Administración de Justicia de 1824, enmendado en 1824, 1836, 1837, 1838, 1851 y 1855, entre otros; y la Ley de 15 de octubre de 1856, sobre procedimiento judicial en asuntos de ciento cincuenta a mil pesos. Esta ley, a su turno, fue complementada por la Ley de organización y atribuciones de los tribunales, de 13 de octubre de 1875, y enmendada por la Ley de 26 de agosto de 1887, sobre forma en que debe hacerse la citación a

Max Huber, 1989), p. I. 9., pp. 35 ss.

${ }^{10}$ Sociedad del Canal de Maipo, cit. (n. 8), p. 3.

${ }^{11}$ Cámara de Senadores, Diario de Sesiones, Sesion [sic] 48 ordinaria, en 26 de Agosto de 1907, p. 1004.

${ }^{12}$ Stewart, Daniel, cit. (n. 7); Figueroa, Luis S., cit. (n. 7). 
los interesados en los juicios sobre distribución de aguas. ${ }^{13}$ Sin perjuicio de lo anterior, debe recordarse también la Ordenanza de 3 de enero de 1872, sobre distribución de las aguas en los ríos que dividen provincias y departamentos, que "estableció el procedimiento para regular la distribución de aguas en rios y canales [...] cualquiera que tuviera interés por un adecuado reparto, podía solicitar al juez competente citara a un comparendo de usuarios del rio o canal para que en él se designara un autoridad encargada de hacer la distribución [...] bajo la mirada de una junta de vigilancia." ${ }^{4}$ Esta ordenanza, que sirvió de base a otras similares para distintos cauces naturales del país, fue complementada por la Ley de 24 de diciembre de 1891, sobre organización y atribuciones de las municipalidades ${ }^{15}$, quedando derogada casi en su totalidad por el título $11^{\circ}$ del libro III del Código de Procedimiento Civil, dictado en 1902, cuyos artículos 823 a 836 trataban acerca de los juicios sobre distribución de aguas, en los cuales se hace referencia nuevamente a los comuneros y a la junta de vigilancia ${ }^{16}$.

Lo interesante de estas comunidades es que los comuneros acordaban un estatuto o reglamento para regular la organización y funcionamiento de la comunidad. El hecho que se acordaran estos estatutos sugería que estas comunidades tenían una fisonomía propia, la que distaba de la comunidad clásica del derecho común que tuvo en mente el Código de Bello. En cierta manera, los comuneros adaptaban también esta institución jurídica -el cuasicontrato de comunidad- a sus necesidades de regadío. Curiosamente, esta adaptación jurídica parecía discurrir sobre el mismo presupuesto jurídico que llevó más tarde a la creación de las comunidades especiales en nuestro derecho, el que podemos deducir de lo aseverado por Somarriva acerca de la indivisión y partición: la comunidad no constituía en estos casos un estado de indivisión pasivo y transitorio, sino más bien un estado de indivisión activo y permanente, que derivaba de la circunstancia que no se trataba de un patrimonio en liquidación. ${ }^{17}$

\footnotetext{
${ }^{13}$ El texto de estas leyes se puede consultar en Anguita, Ricardo, Leyes promulgadas en Chile: Desde 1810 hasta el $1^{\circ}$ de Junio de 1913 (Santiago, Imprenta, Litografía i Encuadernación Barcelona, 1912-1913), 4 volúmenes.

${ }^{14}$ Ibíd. El texto de esta Ordenanza puede consultarse en Venegas, Fortunato, cit. (n. 4), pp. 19-25.

${ }^{15}$ Vergara, Alejandro, Derecho de Aguas (Santiago, Editorial Jurídica de Chile, 1998), II, p. 155.

${ }^{16}$ Stewart, Daniel, cit. (n. 7), p. 102. El texto original del Código de Procedimiento Civil puede ser consultado en García Moreno, Alejo (comp.), Colección de las instituciones politicas y jurídicas de los pueblos modernos. Segunda Serie: Estados modernos. República de Chile (Madrid, Revista de Legislación Universal, 1905), II, pp. $680 \mathrm{~s}$.

${ }^{17}$ Somarriva, Manuel, Indivisión y Partición (4a edición, Santiago, Editorial Ju-
} 
Existen diversos ejemplos de esta práctica asociativa. El estatuto de la Comunidad del Canal de las Perdices, inspirado expresamente en algunos aspectos en el de la Sociedad del Canal de Maipo y acordado en sede judicial, establecía como órgano político a la junta general de accionistas y confiaba la administración a un director y dos sub-directores, los que en parte alguna del reglamento eran identificados colectivamente como directorio o junta directiva. No obstante su denominación, la redacción de este estatuto inducía a cierta confusión, pues aludía en tan sólo una oportunidad a la "comunidad", a propósito de la contribución a los gastos, en su artículo $7^{\circ}$, y en cinco ocasiones a la "Sociedad", a propósito de las obligaciones del Director, destinación del producido de las multas, obligaciones de los dueños de fundos donde corriere el canal y las obligaciones del Director saliente, en sus artículos $5^{\circ}, 14,18$ y $19^{18}$. Este estatuto establecía también obligaciones pecuniarias de cargo de los accionistas, como contribuir a los gastos de la comunidad a prorrata de sus acciones, al igual que normas disciplinarias cuya infracción podía llevar a la imposición de multas a beneficio de la comunidad y a la privación del uso del agua. Mucho más claro en cuanto a la naturaleza jurídica de la organización de usuarios es el reglamento general del Canal Pinto-Solar, pues este estatuto aludía sin ambages a la comunidad o los comuneros en materia de derechos políticos de los comuneros o accionistas, la administración y la jurisdicción del canal, en sus artículos $1,2,3,5^{\circ}, 6,11$ y $12^{19}$.

4. En otras ocasiones, lo que parecía subyacer a la organización de usuarios era un contrato de sociedad primitivo, en base al cual se construyó el canal respectivo. Así, los accionistas de la asociación del Canal de Ochagavía acordaron un reglamento tendiente a regularizar la asociación y mejorar la administración de dicho canal en 1860, en el cual se incorporaron las bases de la sociedad que inició y construyó el citado canal. Este reglamento, aprobado por el Intendente provincial, constaba de veinte artículos, reconocía como accionistas activos solamente a los dueños o representantes de las doce acciones en que se dividió originalmente el canal, establecía como órgano político a una junta general de accionistas y confiaba la administración del mismo a una junta directiva de tres directores. Asimismo, establecía normas disciplinarias, administrativas y jurisdiccionales, muchas

rídica de Chile, 1987), pp. 58, 6166-67.

${ }^{18}$ Comunidad del Canal de las Perdices, Estatutos de la Comunidad del Canal de Las Perdices (Santiago, Impr. de la Unión, 1889), pp. 9-12.

${ }^{19}$ Comunidad de Aguas del Canal Pinto-Solar, Reglamento jeneral aprobado judicialmente, que obliga a todos los comuneros del Canal Pinto-Solar: Reglamento jeneral para los comuneros del Canal Pinto-Solar (Santiago, Impr. El Día, 1891), pp. $1-4$. 
de las cuales decían relación con obligaciones de los accionistas, como por ejemplo la de contribuir a los gastos generales de la asociación ${ }^{20}$. Algo similar parece deducirse del reglamento del Canal de La Pampa, aprobado por el Intendente provincial un año antes, pues su artículo 7 prohibió a los accionistas adoptar medidas que tocaren a la "comunidad de los socios", sin perjuicio de conferir atribuciones a una junta directiva para obrar a nombre de la "sociedad" en materia administrativa y judicial, en sus artículos 8 y $11^{21}$. Del mismo modo, los accionistas de los Canales Yungay y Zapata acordaron un reglamento de gobierno y dirección el 3 de agosto de 1887, cuyo texto reducido a escritura pública el 6 de septiembre de 1887, aludía sin ambages a una "sociedad" o "asociación" en diversos artículos, lo que sugería el origen contractual de la organización de usuarios surgida en dichos cauces artificiales. Este reglamento no difería mucho del caso anterior $^{22}$. Se advierte la misma situación en una asociación pactada en Ovalle, en 1905, para la construcción de un canal que regaría los Llanos de Camarico. Esta asociación se pactó originalmente como una sociedad, cuya administración sería regulada en un reglamento y dio origen más tarde a la Asociación de Canalistas del Canal de Camarico en $1941^{23}$.

5. La naturaleza societaria de una organización de usuarios quedaba de manifiesto cuando sus integrantes pactaban expresamente un contrato de sociedad. Este el caso, hacia fines del siglo XIX, de la Sociedad del Canal de la Calera de Tango, en cuyo estatuto los accionistas del canal expresaron acordarlo, entre otros, para regularizar la personería de una organización de usuarios al parecer preexistente. ${ }^{24}$ Desde luego, el estatuto de esta sociedad no difería mayormente del acordado para reglamentar las comunidades de regantes, arriba mencionadas. El objeto de la sociedad, que determinaba su duración, era la conservación del canal tronco y sus derivados, la mantención del uso y propiedad del agua que se extrae del río Maipo y arreglar y conservar los marcos y cauces existentes y que puedan

${ }^{20}$ Canal de Ochagavía, Reglamento del Canal denominado de Ochagavía (Santiago, Imprenta Nacional, 1863), pp. 2-3, 5-6.

${ }^{21}$ Canal de la Pampa, Reglamento del Canal de La Pampa (La Serena, Impr. de El Coquimbo, 1887), pp. 5, 7-9.

${ }^{22}$ Ver escritura pública extendida con fecha 6 de septiembre de 1887, en la Notaría Pública de Santiago, a cargo de don Mariano Melo Egańa.

${ }^{23}$ Ver escritura pública extendida con fecha 29 de abril de 1905, en la Notaría Pública de Ovalle, a cargo de don Caupolicán Muńoz, cláusula décimo quinta; $<$ www.canalcamarico.cl/quienes-somos/> [consultado el 17 de diciembre de 2008, a las 16:51 PM.].

${ }^{24}$ Sociedad del Canal de la Calera de Tango, Estatutos de la Sociedad del Canal de la Calera de Tango (Santiago, Imprenta y Encuadernacion Roma, 1895), p. 3. 
existir por la distribución de las aguas, según el artículo 1. Al igual que en las comunidades de regantes, los socios no aportaban sus regadores de agua; más bien, el Canal de la Calera de Tango se dividía en 601 acciones o derechos para efectos de la distribución de las aguas, las que se repartían entre los asociados en conformidad a la cantidad de agua que cada uno poseía legítimamente en el canal, de acuerdo al artículo $3^{\circ}$. Dichas acciones incidían en los derechos políticos de los asociados en las juntas generales y sus titulares debían registrarlas en el registro de accionistas de la sociedad, conforme a los artículos 4 y 11 . Asimismo, los asociados no efectuaban un aporte destinado a la constitución de un fondo o capital social al momento de la constitución, sino que simplemente se obligaban a contribuir a los gastos de la sociedad, según los artículos 29 y 30 . Finalmente, la sociedad era administrada por un Consejo Directivo, compuesto de cinco accionistas propietarios y un accionista suplente, que ejercía plenas facultades administrativas y judiciales, de acuerdo a los artículos 6 y $16^{25}$.

6. Cualquiera fuere el origen o forma asociativa empleada para constituir una organización de usuarios de aguas, los estatutos o reglamentos analizados permiten identificar ciertas notas comunes que sugieren un fenómeno jurídico relativamente único y distintivo en el derecho de aguas decimonónico. Estas notas comunes dicen relación con la propiedad de los derechos de aguas en manos de los accionistas, la falta de aporte de los accionistas para la constitución de las organizaciones de usuarios, la regulación de los derechos políticos de los accionistas, y la organización y el funcionamiento interno de tales organizaciones. Estas notas comunes, originadas en la praxis de los usuarios de aguas y los operadores jurídicos, permiten explicar que la organización y funcionamiento de las organizaciones de usuarios fuera muy similar entre todas ellas. Inclusive, un estatuto aplicó expresamente la forma de citación de los accionistas de la Sociedad del Canal de Maipo: la Comunidad del Canal de Las Perdices. ${ }^{26}$ Estas circunstancias sugieren el desarrollo de un proceso de aprendizaje entre usuarios de aguas y operadores jurídicos acerca de la conducencia y beneficios de un modelo organizativo distintivo, basado en aquellas notas comunes, el que atravesaba las diversas formas asociativas adoptadas por ellos. Este modelo organizativo permitió a las organizaciones de usuarios de aguas funcionar por casi setenta años.

Sin embargo, este funcionamiento no estuvo exento de problemas, el principal de los cuales fue la falta de personalidad jurídica de la mayoría de

\footnotetext{
${ }^{25}$ Ibíd., pp. 3-8.

${ }^{26}$ Comunidad del Canal de las Perdices, cit. (n. 18), p. 7.
} 
las organizaciones de usuarios originadas en cuasicontratos de comunidad ${ }^{27}$ y la dudosa juridicidad de las sociedades de usuarios de aguas. Ello llevó a iniciativas tendientes a la reglamentación de las comunidades y asociaciones de regantes y canalistas, entre las que destaca el Proyecto de Código Ruralde don José Victorino Lastarria, de 1875, cuyo título III (artículos 169-177) trataba acerca de las comunidades de regantes, las que eran reguladas "segun los principios del Código Civil, dándoles una organizacion análoga a las de las sociedades legales, bajo la jerencia de un procurador electivo, responsable $i$ alternativo [...]"28, pero que jamás fue aprobado por el Congreso Nacional, y la propuesta de legislación de Venegas, que consta en su recopilación de 1887 y que estaba animada por su percepción sobre la imposibilidad de aplicar el cuasicontrato de comunidad y el contrato de sociedad a predios de reducida extensión, dada "la imposibilidad de fijar con precision la parte o cuota que corresponderia a los comuneros, sobre todo a los dueñor [sic] de pequeños predios" 29 .

Esta situación condujo a la elaboración del proyecto de ley para reglamentar las asociaciones de canalistas, iniciado por el Ejecutivo en 1907, previa aprobación del Consejo de Estado, en cuya exposición de motivos el Ejecutivo hizo presente que: "[1] as numerosas asociaciones de canalistas que se han organizado en Chile con el fin de conservar y mejorar los acueductos $i$ atender al reparto de las aguas entre los asociados en proporcion a sus derechos, no pueden amoldarse ni al tipo de las personas juridicas creadas con arreglo al título final del libro I del Código Civil, ni al de las sociedades industriales de que trata el título XXVIII del libro IV del mismo Código./ Ellas tienen un carácter meramente administrativo i no están destinadas al reparto de beneficios pecuniarios, en lo que se apartan de las sociedades civiles i comerciales; pero se diferencian de las corporaciones a que da vida civil un decreto del Presidente de la República ... en que éstas tienen un fin moral ajeno al derecho de propiedad i no ligan a sus miembros más allá de su vida o del tiempo durante el cual desean quedar adheridos a la institución./ La falta de un organismo legal bajo el cual puedan cobijarse tan útiles creaciones orijina en la práctica graves inconvenientes. / Fuera de la Sociedad del Canal de Maipo, reconocida como persona jurídica por nuestros Tribunales por tener como tal un orijen anterior al Código Civil, es dudoso que las demás comunidades de canalistas tengan igual carácter [...]"30. Este proyecto de ley se convirtió, precisamente, en

${ }^{27}$ Lira, Samuel, cit. (n. 5).

${ }^{28}$ Lastarria, José Victorino, cit. (n. 3), p. 150.

${ }^{29}$ Venegas, Fortunato, cit. (n. 4), pp. $102 \mathrm{~s}$.

${ }^{30}$ Cámara de Senadores, cit. (n. 11). El Consejo de Estado aprobó el proyecto de ley en su sesión de 12 de agosto de 1907. Consejo de Estado, Actas de Sesiones, Vol. 27, 1905 mar. 29-1907 dic. 27, pp. 194 vta. s. 
la Ley No 2.139, de 1908, sobre asociaciones de canalistas, la primera en reglamentar este tipo de organizaciones de usuarios de aguas en nuestro país, la que no derogó las normas sobre juicios de distribución de aguas previstas en el Código de Procedimiento Civil.

\section{OTORGAMIENTO DE ATRIBUCIONES JURISDICCIONALES A LAS ORGANIZACIONES DE USUARIOS DE AGUAS}

1. El estudio de los estatutos o reglamentos de las organizaciones de usuarios de aguas permite constatar el otorgamiento de atribuciones jurisdiccionales a uno o más de sus órganos internos, especialmente administrativos, con el objeto de resolver los conflictos derivados del ejercicio de los derechos de sus integrantes, empleando para ello diversas instituciones jurídicas ${ }^{31}$. Una visión de conjunto de estos instrumentos permite establecer cinco opciones distintas de diseño institucional, a lo menos, respecto del otorgamiento de atribuciones jurisdiccionales a dichas organizaciones de usuarios, entre los años 1831 a 1908. En más de alguna ocasión ellos establecieron una verdadera jurisdicción de segundo grado, contemplando un recurso de apelación en contra de tribunales internos de primer grado, mientras que en otra ocasión un estatuto autorizó a los agraviados para ocurrir ante el Intendente provincial. La nota subyacente a estas normas estatutarias fue la de resolver estos conflictos al interior de las organizaciones de usuarios, con el objeto de evitar que éstos se ventilaran ante órganos externos a la organización. Sin embargo, una revisión de las principales revistas de jurisprudencia de la época revela que, al parecer, los Tribunales se pronunciaron acerca de la validez de una sola de dichas opciones de diseño institucional (la empleada por la Sociedad del Canal de Maipo), no existiendo sentencias judiciales publicadas que hayan recaído en las restantes opciones de diseño institucional.

2. La primera opción de diseño institucional -y la más antigua- fue la de la Sociedad del Canal de Maipo, que databa de 1831. Ella consistió en conferir a la Junta de Directores el carácter de juez único, privativo y de árbitro arbitrador, tanto respecto de los conflictos de la sociedad con los accionistas y de los accionistas entre sí. Así, la Junta General de Accionistas adoptó, a propuesta de la Junta de Directores, el acuerdo de 3 de noviembre de 1831, en el cual interpretó el Acta de Asociación de 1827, aludiendo por primera vez a la jurisdicción arbitral del directorio. El Acuerdo expresó,

${ }^{31}$ La única excepción, entre los estatutos estudiados, la constituye el del Canal de la Cañada de Curicó, acordado en sede judicial y que data de 1893. CANAL DE LA Cañada (Curicó), Estatutos para el Canal de la Cañada (Curicó) (Santiago, Imprenta y Encuadernación Barcelona, 1893), 16 pp. 
en lo pertinente, lo siguiente: "La Junta General de accionistas del Canal de Maipo, en sesion de este dia ha acordado declarar: que por consecuencia necesarias de nuestro pacto de asociacion i acuerdos de la Junta Jeneral, son atribuciones de la junta de directores:/ [...] 3. ${ }^{\circ}$ Cumplir i hacer que cada socio cumpla los acuerdos de la Junta Jeneral, declarando incursos en las multas $i$ otras penas, que por dichos acuerdos o por la de directores se impongan a los infractores de lo establecido en la asociacion, $i$ hacerlas efectivas, usando de la fuerza si fuera necesario./ [...] $6 .^{\circ}$ El socio que se creyere agraviado por las providencias de la junta de directores, está facultado para pedir que se de cuenta en primera ocasion a la jeneral, sin impedir por este reclamo la pronta ejecucion de lo resuelto./[...] 10. Que para solidar mas el pacto de asociacion, i evitar en lo sucesivo los graves males que se le han inferido por los recursos que han promovido algunos socios, la Junta Jeneral de accionistas reunida conforme a los convenido en las bases, declara que la junta de directores es el único y privativo juez de los negocios $i$ disputas concernientes a los derechos que han unido en la compañia; que están sometidos i que nuevamente se someten a ellos, como árbitros arbitradores, renunciando todo recurso i leyes que les favorezcan, para que dichos directores resuelvan i procedan con estas facultades, según sus atribuciones i reglamentos que tenemos en la compañia. $[\ldots] " 32$. El acuerdo concluyó solicitando "[q] ue los directores supliquen al Supremo Gobierno se digne hacer circular a los tribunales i autoridades locales el pacto primario i los principales acuerdos posteriores de nuestra asociacion, formada en consecuencia de su supremo decreto, para que seamos juzgados por ellos o repelido el que intente contra los pactos, i los directores auxiliados $i$ amparados en el cumplimiento de sus deberes $i$ atribuciones"33.

La Junta de Directores requirió la aprobación del Presidente de la República, don José Joaquín Prieto, respecto del Acta de Asociación y sus acuerdos complementarios, adoptados entre 1827 y 1831, como una forma de solemnizar su contenido y darles el carácter de estatutos sociales. Requerido su informe previo por el Ejecutivo, el Ministerio Fiscal estimó que la solicitud de la Junta de Directores era justa e interesante al bien público, atendidos los antecedentes sobre la compañía, por lo que no encontró inconveniente para acceder a ella. Por ello, el Fiscal, Sr. Elizalde, sostuvo que las normas sociales se ajustaban a derecho, pues " $[1]$ as leyes porque se nivela una compañía son las condiciones que se fijan los asociados, como no sean opuestas al bien público, a las costumbres, etc.: por consiguiente, cada uno puede obligarse del modo que quiera, i en efecto queda obligado" ${ }^{34}$.

\footnotetext{
${ }^{32}$ Sociedad del Canal de Maipo, cit. (n. 8), pp. 15 ss.

${ }^{33}$ Ibíd., p. 17.

${ }^{34}$ Ibíd., p. 5.
} 
Además, él vio una gran ventaja procesal en los acuerdos adoptados, porque: "[...] no serán distribuidas sus atenciones con los muchos pleitos que necesariamente resultan en una compañia tan dilatada [...] i en la que no pueden faltar litigantes maliciosos que bajo la proteccion de las fórmulas judiciales eternizarian las acciones y retendrian los pagos mas justos con gravámen de los demas accionistas i perjuicio de la empresa” 35 . El Presidente de la República, a su turno, aprobó el Acta de Asociación y sus acuerdos complementarios mediante el Decreto de 3 de marzo de 1832, antes citado. Este decreto expresó que: "[...] recomienda a los tribunales de justicia tengan presente los compromisos que han contraido entre si los accionistas del Canal de Maipo para no introducirse a juzgar en las discordias que se suscitaren entre ellos, habiendo renunciado solemnemente la comparecencia a los jueces públicos, $i$ obligándose a deslindar sus derechos por si mismo $[\ldots]^{36}$.

Esta jurisdicción arbitral generó un par de controversias entre los accionistas, una de las cuales terminó ventilándose en el foro. La primera de ellas dijo relación con la procedencia de recursos judiciales en contra de las resoluciones de la Junta de Directores. Al respecto, la Junta General de Accionistas, conociendo de la apelación interpuesta por un accionista en contra de una resolución dictada por la Junta de Directores, resolvió el 12 de septiembre de 1864 que: "[h] abiendo pedido D. Ricardo Ovalle que la Junta General entendiese en la apelación de la sentencia de la Junta de Directores de fecha 7 de septiembre de 1863, después de un lijero debate en que tomaron parte D. Francisco Vargas Fontecilla y D. Waldo Silva, se acordó: que según el articulo 10 de acuerdos celebrados el 3 de noviembre de 1831, ninguna sentencia pronunciada por la Junta de Directores podía tener apelación a la Junta General [...]" ${ }^{37}$. La segunda, ciertamente más importante, dijo relación con la competencia absoluta de la Junta de Directores para resolver las cuestiones entre los accionistas y la sociedad. Ella fue ventilada en el juicio "Donato Millán con Canal de Maipo", cuya sentencia de término, acordada por un voto de mayoría en la Corte Suprema, confirmó indirectamente la competencia absoluta de la Sociedad del Canal de Maipo respecto de tales cuestiones. En la especie, el Sr. Millán demandó a esta sociedad ante un juzgado de letras, el que se declaró incompetente, y posteriormente ante un juzgado especial de hacienda, solicitando que se declarara que la sociedad carecía de derecho para privarle del uso del agua por no pago de una multa y exigirle el pago de diversos desembolsos

${ }^{35}$ Ibíd., pp. 5 s.

${ }^{36}$ Ibíd., p. 6.

${ }^{37}$ Sociedad del Canal de Maipo, Recopilación ordenada de los Estatutos y de las Disposiciones Reglamentarias de la Sociedad del Canal de Maipo (Santiago, Imprenta Cervantes, 1899), p. 15 nota I. 
derivados de la presunta infracción de sus acuerdos, como asimismo, que ella debía indemnizarle los perjuicios ocasionados por la privación del agua. La sociedad interpuso una excepción de incompetencia del tribunal, solicitando que se declarara que ella no estaba obligada a contestar la demanda y se ordenara al actor ejercer sus derechos conforme a los estatutos sociales, debido a que él era uno de los accionistas de la sociedad y estaba sujeto a los acuerdos de su Junta General de Accionistas. El juzgado especial de hacienda rechazó la excepción mediante sentencia de 23 de septiembre de 1887 y la sociedad apeló para ante la Excma. Corte Suprema, la que revocó el fallo de primer grado y acogió la excepción interpuesta, mediante sentencia definitiva de 11 de mayo de 1888, declarando que la sociedad no estaba obligada a contestar la demanda interpuesta en su contra. El fallo de mayoría, de los Ministros Sres. Covarrubias y Abalos, señaló, en lo pertinente, que: "[c]onsiderando:/ Que la Sociedad del Canal de Maipo se gobierna por los estatutos, reglamentos o acuerdos jenerales que ella misma ha hecho para su administracion $i$ réjimen interior, reglamentos $i$ estatutos que son obligatorios para Millan, como accionista a las aguas de uno de los canales que se hallan bajo la direccion i vigilancia de la Sociedad; / [...] Que segun lo dispuesto en el núm. 10 del acuerdo de 3 de noviembre de 1831, el socio que se creyere agraviado por las providencias de la junta de directores, está facultado para pedir que se de cuenta en primera ocasion a la junta jeneral de accionistas sin impedir por este reclamo la pronta ejecucion de lo resuelto por el directorio; [ [...] Que aunque la sociedad declinó oportunamente de la jurisdicción ordinaria i pidió que el conocimiento de la causa pasara al juez especial de hacienda, por tener interes el fisco en dicha sociedad; formuló la declinatoria espresando que ante el juzgado de hacienda alegaria la competencia del directorio para resolver sobre las cuestiones de los socios como lo ha hecho en efecto./ En mérito de las consideraciones que preceden i visto lo dispuesto en los arts. 1545 y 1546 del Código Civil, se revoca el auto apelado de 23 de setiembre de 1887, corriente af. 56, i se declara que la Sociedad del Canal de Maipo no está obligada a contestar la demanda interpuesta por el mencionado 
don Donato Millan, pudiendo éste hacer uso de sus derechos ante quien viere convenirle $[\ldots]^{38}$. Hasta aquí el fallo ${ }^{39}$.

3. Una ligera variante de esta primera opción de diseńo institucional la encontramos en los reglamentos del Canal de Ochagavía y de los Canales Yungay y Zapata, como asimismo, en el estatuto del Canal de La Herradura, este último acordado en sede judicial. El reglamento del Canal de Ochagavía confiaba la dirección del canal a una Junta Directiva compuesta de tres directores propietarios, elegidos por mayoría de votos en junta general de accionistas, a la que confería atribuciones jurisdiccionales con exclusión de otra autoridad, so pena de multa. En tal sentido, el artículo 20 del reglamento prescribía que: "[1] a junta directiva juzga sin apelacion toda diferencia que en lo relativo a asuntos del canal ocurra entre los asociados o entre estos $i$ la administracion i sus empleados. El accionista o asociado, que no conformándose con esta disposicion, ocurra a otras autoridades sobre cuestiones relacionadas con el servicio del canal, incurrirá en multa de doscientos pesos a beneficio de la sociedad"40. El reglamento de los Canales Yungay y Zapata contemplaba una norma muy similar, pues su Junta Directiva tenía atribuciones para "juzgar sin apelacion toda diferencia que sobre asuntos administrativos del canal ocurra entre los accionistas, o entre estos i los empleados de la Sociedad"41, como indicaba su artículo 16 No 9. Sin embargo, el mismo reglamento dejaba a salvo la acción de los accionistas ante la justicia ordinaria, respecto de la aplicación de sanciones por parte de la sociedad, consistentes en multas y la privación del agua, derivadas de la alteración de marcos, formación de tacos, o algún otros "fraude" en la distribución de las aguas, como lo indicaba el artículo $15^{42}$.

${ }^{38}$ Corte Suprema, “Donato Millan con Canal de Maipo", sentencia $N^{\circ} 700$, en GT. 2, 488 (1888), p. 554. A pesar que en el índice temático de las sentencias civiles publicadas en el tomo I, desde el 1 de Marzo de 1888 hasta el 31 de Agosto de 1888, de la Gaceta de los Tribunales, la sentencia indicada aparece referida a "Derechos sobre Aguas" (p. 1426), el título consignado al inicio de su transcripción indica como materia "competencia." Este fallo tiene un importante voto de minoría, redactado por el Ministro Sr. Cousiño, quien sostenía que esta jurisdicción contrariaba la ley, la Constitución Política y el orden público. Ibíd., p. 555.

${ }^{39}$ Don Manuel E. Ballesteros trajo a colación este fallo en su comentario, escrito dos años más tarde, sobre el artículo 175 de la Ley de Organización y Atribuciones de los Tribunales, de 15 de octubre de 1875, que prohibía nombrar árbitro para la resolución de un asunto al juez que estuviere conociendo de él y a las personas que litigaren como partes. Ballesteros, Manuel E., La Lei de Organizacion i Atribuciones de los Tribunales de Chile (Santiago, Imprenta Nacional, 1890), II, pp. 86, 759.

${ }^{40}$ Canal de Ochagavía, cit. (n. 20), p. 6.

${ }^{41}$ Cit. (n. 22).

${ }^{42}$ Ibíd. 
El estatuto del Canal de la Herradura difería ligeramente del anterior, porque contemplaba la posibilidad de reclamar de los fallos del órgano administrativo. Este estatuto confiaba la administración del canal a una Junta Directiva, la que gozaba de plenas atribuciones administrativas, siendo sus deliberaciones "ejecutivas e inapelables" al tenor del artículo $9^{\circ}$. Esta Junta Directiva también gozaba de atribuciones jurisdiccionales, pues conocía de las acciones de los accionistas y comuneros, mientras que sus actuaciones y resoluciones abusivas eran reclamables para ante la Junta General de Accionistas y Comuneros. En tal sentido, el artículo 10 preceptuaba que: "[a]l presidente de la Junta es ante quien debe ocurrirse para la interposicion de las querellas que se ocurran, i éste en su virtud dará la órden de citacion para la reunion de los otros dos directores, o citará a Junta Jeneral, segun el caso lo exija." El artículo 19, a su turno, prescribía que: "[d] e los abusos que cometa la Junta Directiva en el ejercicio de sus funciones, conocerá la Junta Jeneral de accionistas y comuneros, i el fallo de ésta será ejecutivo e inapelable." Presidiendo este sistema de resolución de conflictos se encontraba también la exclusión estatutaria de toda otra autoridad, so pena de multa y de no ser oído, pues el artículo 17 señalaba perentoriamente que "[n] ingun accionista ni comunero podrá bajo razon o pretesto alguno, ocurrir a la Justicia ordinaria o autoridad gubernativa, a querellarse de las penas y demas que impone el presente reglamento bajo la multa de doscientos pesos $i$ a mas la pena de no ser oido" 43 .

4. Una segunda opción de diseño institucional se encuentra en el estatuto de la Sociedad del Canal de la Calera de Tango, que establecía tribunales de primer y segundo grado al interior de la sociedad. El estatuto confería a un Consejo Directivo, compuesto de cinco accionistas, "plenas facultades judiciales y administrativas" y agregaba que su jurisdicción se extendía "hasta el último marco partidor de las aguas de la sociedad", según los artículos 6 y 22 , respectivamente. Sin embargo, el estatuto configuraba las atribuciones jurisdiccionales de este Consejo Directivo de manera distinta a los anteriores, distinguiendo entre los directores individualmente considerados y el Consejo como órgano colectivo. Respecto de los primeros, los artículos 21, 22 y 23 preceptuaban que los asuntos contenciosos o reclamos de los accionistas entre sí se interponían ante el presidente del Consejo, quien ordenaba que se sustanciaran en primera instancia por uno de los directores, denominado Director de Turno, y que se fallaran posteriormente por otro director, una vez concluida su tramitación. Con todo, la competencia del tribunal de primer grado era más amplia de lo que

${ }^{43}$ Canal de la Herradura, Estatutos de comuneros (La Serena, Imprenta "El Coquimbo", 1896), pp. 5 s. 
sugería esta disposición, atendido el tenor de la competencia del tribunal de segundo grado, como se indica más adelante. El artículo 23 contemplaba incluso la posibilidad de recibir la causa a prueba ante el tribunal de primer grado, cuando la cuestión fuere de hecho y las partes quisieran rendir prueba. De acuerdo al artículo 25, ni el director tramitador, ni el sentenciador, podían estar inhabilitados por alguna causa de implicancia o recusación contemplada en la legislación común; de lo contrario, los accionistas ("las partes") podían solicitar la exclusión de los directores inhábiles dentro de tercero día, contado desde la citación, incidencia que era conocida y resuelta por tres directores no impedidos. Respecto del segundo, el artículo 19 No 6. establecía que era atribución del Consejo: "[j] uzgar en apelación y sin ulterior recurso toda diferencia ó reclamo que se suscite entre los accionistas sobre el uso de sus derechos de aguas, sobre reforma ó variación de marcos, sobre corrección de abusos y transgresiones de estos estatutos, sobre imposición de multas y sobre mal cumplimiento de sus deberes en los empleados de la sociedad"44.

5. Una tercera opción de diseño institucional la encontramos en el estatuto de la Comunidad del Canal de Las Perdices, el que también establecía tribunales de primer y segundo grado al interior de la comunidad, pero radicados en el Director (y subdirectores, en su caso) y en la Junta General de Accionistas, respectivamente. El estatuto confiaba la administración de la comunidad a un Director, quien era asistido para negocios puntuales por dos subdirectores. De acuerdo al artículo 5, el Director debía "[a] tender y resolver las quejas de los accionistas entre si o contra los empleados de la Sociedad, haciéndolo con la mayor prontitud posible $e^{45}$. Para estos efectos, el Director podía conocer y resolver por sí solo estas reclamaciones o "[a] sociarse con los subdirectores para resolver los reclamos de los accionistas, cuando éstos lo solicitaren asî" ${ }^{46}$. De las resoluciones del Director podía reclamarse ante la Junta General Ordinaria de Accionistas, la que conforme al estatuto "conocerá finalmente y decidirá en única instancia de los reclamos que puedan tener los accionistas contra las determinaciones que hubiera tomado el Director" 47.

6. Una cuarta opción de diseño institucional -la más simple de todasse encuentra en el estatuto de los comuneros del Canal Pinto-Solar, el que por una parte confería atribuciones administrativas a un Administrador y por otra parte confería atribuciones jurisdiccionales a dos accionistas, designados en la reunión anual de comuneros, para conocer de las reclama-

\footnotetext{
${ }^{44}$ Sociedad del Canal de la Calera de Tango, cit. (n. 24), p. 10.

${ }^{45}$ Comunidad del Canal de las Perdices, cit. (n. 18), p. 9.

${ }^{46}$ Ibíd.

${ }^{47}$ Ibíd., p. 8.
} 
ciones interpuestas en contra de las resoluciones de aquél que importaren la privación del agua. En tal sentido, el artículo 11 prescribía que: "[e]n la reunion anual de comuneros, se designará a dos accionistas para que, con la calidad de Arbitros, aprueben o desaprueben las resoluciones del Administrador, en cuanto puedan éstas importar una privacion de agua durante mas de veinticuatro horas, en cada caso./ La apelacion deberá interponerse por escrito, dentro de los cinco dias siguientes a la notificacion hecha al propietario, arrendatario o mayordomo del predio." No obstante el tenor de esta disposición, se trataba en realidad de una reclamación en contra de las resoluciones del Administrador, interpuesta ante un tribunal arbitral, que estaba compuesto de dos accionistas, dentro del plazo de cinco días siguientes a la notificación de la privación del agua por más de veinticuatro horas, y cuyas resoluciones no eran susceptibles de recurso alguno, pues el estatuto no creó un tribunal de segundo grado. Por lo expuesto, huelga decir que todos los restantes conflictos, tanto de los accionistas entre sí y con la comunidad, quedaban entregados al conocimiento y resolución de la jurisdicción ordinaria.

7. Una quinta opción de diseño institucional se encuentra contemplada en el reglamento del Canal La Pampa, el cual otorgaba atribuciones jurisdiccionales a un órgano administrativo, la Junta Directiva, pero no excluía eventualmente del conocimiento de dichos negocios a órganos externos a la comunidad. Los artículos 8 y 9 del reglamento confiaban a una junta de tres accionistas - "notoriamente competentes" - la dirección del canal con amplias facultades, la que era nombrada ante el intendente provincial por "votación directa" de los accionistas. En materia jurisdiccional, el reglamento confería también a esta Junta Directiva atribuciones jurisdiccionales para conocer de los conflictos entre accionistas y entre éstos y la comunidad. Al respecto, el artículo 11 No 13 inciso $1^{\circ}$ prescribía que la Junta Directiva debía: "[e]ntender en las cuestiones que puedan suscitarse entre los accionistas sobre asuntos peculiares del canal i tanto en esto, como en la aplicación de las multas, [...] i en todo lo demas que disponga en ejercicio de sus deberes: sus resoluciones serán inapelables" ${ }^{38}$. Sin embargo, esta competencia podía cesar eventualmente, como asimismo, las actuaciones judiciales respectivas podían ser revisadas por un órgano externo, en caso de que la Junta Directiva no pudiere resolver las cuestiones antedichas o abusare de sus atribuciones. En tal sentido, el artículo 11 No 13 inciso $2^{\circ}$ agregaba: "Pero si la Junta no pudiere dirimir las contiendas entre los socios, o si ella abusare de las atribuciones que le son conferidas por este reglamento, entónces podrá ocurrir el que se sintiere agraviado ante el señor Intendente de

${ }^{48}$ Canal de la Pampa, cit. (n. 21), p. 8. 
la provincia, quien, informado del reclamo determinará sin ulterior recurso lo que estime de justicia" ${ }^{39}$.

8. El análisis precedente pone de manifiesto la existencia de cinco opciones distintas de diseńo institucional en materia jurisdiccional, a lo menos, en el establecimiento de organizaciones de usuarios de aguas entre los años 1831 a 1908. Es difícil determinar si uno o más de estos diseños institucionales fue eficaz y eficiente en la administración de los conflictos entre asociados de organizaciones de usuarios, pues semejante juicio implica el análisis de evidencia que, de existir, no parece estar actualmente disponible. Por otra parte, una revisión de las principales revistas de jurisprudencia de la época revela la existencia de un solo fallo judicial publicado en la materia, el cual confirmó mediante un voto de mayoría la competencia judicial absoluta del órgano administrativo de una organización de usuarios de aguas: nos referimos al fallo "Donato Millán con Canal de Maipo". Lo anterior complementa hallazgos previos de este autor sobre el origen de la jurisdicción arbitral en el derecho de aguas chileno y proporciona una visión general acerca de las diversas opciones de diseño institucional que existían en la materia hacia principios del siglo $\mathrm{XX}^{50}$.

Considerando que el legislador adoptó en 1908 una versión ligeramente modificada del diseńo institucional implementado en materia jurisdiccional por la Sociedad del Canal de Maipo, surge la interrogante acerca de la razón que pudo haber llevado a tal decisión legislativa. $\mathrm{Al}$ respecto, la circunstancia de haber sido confirmada en sede judicial la personalidad jurídica de la Sociedad del Canal de Maipo pudo haber movido al Ejecutivo a sostener la bondad de su jurisdicción arbitral, como se desprende de la exposición de motivos del proyecto de ley sobre asociaciones de canalistas, en la que señaló que: "[f] uera de la Sociedad del Canal de Maipo, reconocida como persona jurídica por nuestros Tribunales por tener como tal un orijen anterior al Código Civil, es dudoso que las demas comunidades de canalistas tengan igual carácter. [...] La jurisdiccion que se arrogan los directorios no está en armonía con la lei de Tribunales./ [...] La administración de los canales de regadio requiere unidad, enerjía i prontitud de accion, lo que no se puede conseguir sino dando a los directorios de los canales amplias facultades administrativas, moderadas solamente por las atribuciones que se reservan a las juntas de socios, i una jurisdiccion de efectos inmediatos. In este punto la lei vendria a generalizar el réjimen análogo que tan buenos resultados ha dado en tres cuartos de siglo en la Sociedad del Canal de Maipo./ Pero como

${ }^{49}$ Ibíd., pp. 8 s.

${ }^{50}$ Оваndo, Iván, Los orígenes de la jurisdicción arbitral en el Derecho de aguas chileno, en Ius et Praxis 11 (2005) 2, pp. 157-196. 
no es posible dejar a los dueños de agua bajo el peso de una autoridad tan omnimoda, el proyecto establece que sin perjuicio de la ejecucion inmediata de las órdenes i resoluciones del directorio, haya recurso a la justicia ordinaria en resguardo de los derechos que se consideren lesionados por el directorio" ${ }^{21}$. Estas palabras parecían sugerir que la jurisdicción arbitral de aquella sociedad había logrado un grado de eficacia y eficiencia en el cumplimiento de sus fines. ${ }^{52}$ Esta apreciación parece haber sido compartida incluso por algún detractor del proyecto de ley, como el $\mathrm{H}$. Senador Balmaceda, cuyas críticas dejaban entrever cierta eficacia y eficiencia del diseño institucional implementado en materia jurisdiccional por la Sociedad del Canal de Maipo, al sostener que "[p] ara dictar una lei como ésta no podemos basarnos en los estatutos tiránicos de la Sociedad del Canal de Maipo, sino que debemos lejislar de una manera equitativa y justa./ [...] Si se agrega que por lo que respecta a la Sociedad del Canal de Maipo no hai a quien reclamar, i que esta Sociedad [sic] está fuera de la lei, i nadie puede reclamar ante la justicia ordinaria de las disposiciones de su directorio, se verá que esto es irritante"53. Adicionalmente, la confirmación judicial de la personalidad jurídica de la Sociedad del Canal de Maipo implicaba que su estatuto social, incluido su diseño institucional de una jurisdicción arbitral a cargo del directorio, podía servir de modelo para otras organizaciones de usuarios de aguas, como se desprende de las palabras del H. Diputado Huneeus, quien sostuvo derechamente que: "[e]lproyecto que discutimos tiene por objeto aprovechar la situacion en que ha dejado a la Sociedad del Canal de Maipo una sentencia de los Tribunales de Justicia, reconociendo su personalidad jurídica, en vista de haber sido constituida con anterioridad al Código Civil"54.

Con todo, la validez de dicha jurisdicción arbitral había sido confirmada en el fallo de mayoría recaído en "Donato Millán con Canal de Maipo", dictado por la Corte Suprema en 1888 y este mismo Tribunal, por medio de otro fallo de mayoría recaído en "Echeverría con Club Hípico", dictado en 1905, había resuelto en sentido contrario en un caso relativo

${ }^{51}$ CÁmara de Senadores, cit. (n. 11), pp. $1004 \mathrm{~s}$.

${ }^{52}$ Una prueba temprana de este aserto la encontramos en el proyecto de ley de fomento y auxilio a la construcción de represas y canales para el regadío de los campos, presentado en la Cámara de Diputados por el H. Diputado don Joaquín Díaz B. en 1898 y cuyo artículo 12 declaraba a las comunidades beneficiarias de las nuevas obras de regadío constituidas en sociedad y sujetas a las reglas de la Sociedad del Canal de Maipo, una vez contratadas las obras respectivas. CÁmara de Diputados, Boletín de Sesiones, Sesion [sic] 24. a estraordinaria en 22 de Diciembre de 1898, pp. 421-425.

${ }^{53}$ Cámara de Senadores, Diario de Sesiones, Sesion [sic] 12. a ordinaria en 30 de Junio de 1908, pp. 251, 253.

${ }^{54}$ Cámara de Diputados, Boletín de Sesiones, Sesion [sic] $41 .{ }^{\mathrm{a}}$ ordinaria en $1 .^{\circ}$ de Setiembre de 1908, p. 1282. 
a una persona jurídica ligada a una actividad económica distinta, por lo que la validez de la jurisdicción de una organización de usuarios de aguas podía ser eventualmente debatida en estrados judiciales de nuevo ${ }^{55}$. En este punto, la circunstancia que uno de los autores del proyecto de ley sobre asociaciones de canalistas fuera don Carlos Aldunate Solar, quien fuera por largos años abogado de la Sociedad del Canal de Maipo y un experto reconocido en legislación de regadío, incidió en que el citado proyecto de ley se basará en el estatuto social de aquella sociedad ${ }^{56}$, al punto que el Ministro de Industria y Obras Públicas de la época., Sr. Figueroa, reconoció en el hemiciclo del Senado que: "[e]n el hecho, la sociedad del Canal de Maipo sigue, puede decirse, a la letra las disposiciones contenidas en este proyecto" 57 .

\section{CONCLUSIONES}

1. Este artículo analizó las organizaciones de usuarios de aguas existentes con anterioridad a la emisión de la Ley $\mathrm{N}^{\circ} 2.139$, de 1908, que reguló las asociaciones de canalistas. Este análisis tuvo por objeto determinar cuáles fueron las formas asociativas empleadas concretamente por los regantes para organizarse jurídicamente y si estos últimos confirieron atribuciones jurisdiccionales a dichas organizaciones para resolver los conflictos derivados del ejercicio de los derechos de sus asociados. Responder este par de interrogantes permitió precisar, mediante el análisis de evidencia documental, los comentarios generales de la doctrina en la materia y complementar hallazgos previos del autor sobre el origen de la jurisdicción arbitral en el derecho de aguas chileno, proporcionado así una visión más acabada sobre el repertorio organizacional e instituciones utilizadas por los usuarios de aguas antes de 1908.

Para estos efectos, este artículo constató que los usuarios de aguas se organizaron jurídicamente mediante el cuasicontrato de comunidad y el contrato de sociedad, empleando instrumentalmente las instituciones jurídicas vigentes, dada la inexistencia de un cuerpo legal que regulara

${ }^{55}$ Ver fallo de la Excma. Corte Suprema recaído en el recurso de casación en el fondo interpuesto en el juicio "Echeverría con Club Hípico", de 20 de diciembre de 1905, en Revista de Derecho y Jurisprudencia 9 (Agosto de 1906), 2º parte, sección $1^{\mathrm{a}}$, pp. 349-360. Interesantemente, varios de los fundamentos del fallo de mayoría recuerdan el voto de minoría del fallo recaído en "Donato Millán con Fisco", redactado por el Ministro Sr. Cousińo.

${ }^{56}$ Obando, Iván, cit. (n. 50), pp. 176-179.

${ }^{57}$ Cámara de Senadores, Diario de Sesiones, Sesion [sic] 10. ordinaria en 23 de Junio de 1908, p. 204. 
especialmente la organización y funcionamiento de las organizaciones de usuarios de aguas. Esta constatación permitió identificar ciertas notas comunes a todas las organizaciones de usuarios de aguas jurídicamente organizadas, las que decían relación con la propiedad de los derechos de aguas en manos de los accionistas, la falta de aporte de los accionistas para la constitución de las organizaciones de usuarios, la regulación de los derechos políticos de los accionistas, y la organización y el funcionamiento interno de tales organizaciones. Estas notas comunes, originadas en la praxis de los usuarios de aguas y los operadores jurídicos, permitieron explicar que la organización y funcionamiento de las organizaciones de usuarios fuera muy similar entre todas ellas, no obstante la forma asociativa empleada concretamente por los usuarios de aguas.

Las circunstancias antedichas sugirieron el desarrollo de un proceso de aprendizaje entre usuarios de aguas y operadores jurídicos acerca de la conducencia y beneficios de un modelo organizativo distintivo, basado en aquellas notas comunes, el que atravesaba las diversas formas asociativas adoptadas por ellos. Este modelo organizativo permitió a las organizaciones de usuarios de aguas funcionar por casi setenta años, hasta la emisión de la Ley No 2.139, de 1908, la que estableció una vía jurídica para solucionar ciertos problemas de su funcionamiento, especialmente la falta de personalidad jurídica de la mayoría de las organizaciones de usuarios originadas en cuasicontratos de comunidad y la dudosa juridicidad de las sociedades de usuarios de aguas.

Del mismo modo, este artículo estableció que los usuarios de aguas confirieron atribuciones jurisdiccionales a las organizaciones jurídicas de usuarios por ellos creadas, con el objeto de resolver los conflictos derivados del ejercicio de los derechos de los asociados, en aquellos casos en que los estatutos o reglamentos respectivos contemplaron normas al respecto. Este análisis reveló que varias de estas organizaciones otorgaron tales atribuciones jurisdiccionales a sus órganos administrativos, identificando la existencia de cinco opciones de diseño institucional, a lo menos, para efectos del otorgamiento de estas atribuciones entre los ańos 1831 a 1908. La falta de evidencia impidió evaluar tales opciones de diseño institucional en términos de su eficacia y eficiencia; sin embargo, un fallo judicial de mayoría dictado en "Donato Millán con Canal de Maipo", en 1888, confirmó la competencia judicial absoluta del órgano administrativo de la Sociedad del Canal de Maipo. La validez de esta jurisdicción podía estimarse en entredicho hacia principios del siglo XX, debido a que la Excma. Corte Suprema, por medio de otro fallo de mayoría recaído en "Echeverría con Club Hípico", dictado en 1905, había resuelto en sentido 
contrario en un caso relativo a una persona jurídica ligada a una actividad económica distinta.

No obstante, el Ejecutivo se basó en el estatuto de la Sociedad del Canal de Maipo para elaborar el proyecto de ley sobre asociaciones de canalistas en 1907, lo que incluía el diseño institucional implementado por aquélla para resolver los conflictos derivados del ejercicio de derechos de sus asociados, esto es, la jurisdicción arbitral del directorio. En los hechos, el proyecto contempló una versión ligeramente modificada de este estatuto, pero no alteró sus lineamientos esenciales. En este punto, la circunstancia que uno de los autores del proyecto de ley sobre asociaciones de canalistas fuera don Carlos Aldunate Solar, quien fuera por largos años abogado de la Sociedad del Canal de Maipo y un experto reconocido en legislación de regadío, incidió en que el citado proyecto de ley se basará en el estatuto social de aquella sociedad.

[Recibido el 19 de marzo y aceptado el 12 de mayo de 2009 ].

\section{BIBLIOGRAFÍA}

Anguita, Ricardo, Leyes promulgadas en Chile: Desde 1810 hasta el $1^{\circ}$ de Junio de 1913 (Santiago, Imprenta, Litografía i Encuadernación Barcelona, 1912-1913), 4 volúmenes.

Ballesteros, Manuel E., La Lei de Organizacion i Atribuciones de los Tribunales de Chile (Santiago, Imprenta Nacional, 1890), II.

Cámara de Diputados, Boletín de Sesiones, Sesion [sic] 24. a estraordinaria en 22 de Diciembre de 1898.

Cámara de Diputados, Boletín de Sesiones, Sesion [sic] $41 .^{\mathrm{a}}$ ordinaria en $1 .^{\circ} \mathrm{de}$ Setiembre de 1908, p. 1282.

Cámara de Senadores, Diario de Sesiones, Sesion [sic] $10 .^{a}$ ordinaria en 23 de Junio de 1908.

Cámara de Senadores, Diario de Sesiones, Sesion [sic] $12 .^{a}$ ordinaria en 30 de Junio de 1908.

Cámara de Senadores, Diario de Sesiones, Sesion [sic] 48a ordinaria, en 26 de Agosto de 1907.

Canal de la Cañada (Curicó), Estatutos para el Canal de la Cañada (Curicó) (Santiago, Imprenta y Encuadernación Barcelona, 1893).

Canal de la Herradura, Estatutos de comuneros (La Serena, Imprenta "El Coquimbo", 1896).

Canal de la Pampa, Reglamento del Canal de La Pampa (La Serena, Impr. de El Coquimbo, 1887).

Canal de Ochagavía, Reglamento del Canal denominado de Ochagavía (Santiago, Imprenta Nacional, 1863).

Comunidad de Aguas del Canal Pinto-Solar, Reglamento jeneral aprobado judi- 
cialmente, que obliga a todos los comuneros del Canal Pinto-Solar: Reglamento jeneral para los comuneros del Canal Pinto-Solar (Santiago, Impr. El Día, 1891).

Comunidad del Canal de las Perdices, Estatutos de la Comunidad del Canal de Las Perdices (Santiago, Impr. de La Unión, 1889).

Consejo de Estado, Actas de Sesiones, Vol. 27, 1905 mar. 29-1907 dic. 27.

Corte Suprema, "Donato Millan con Canal de Maipo", sentencia N ${ }^{\circ} 700$, en GT. 2, 488 (1888).

"Echeverría con Club Hípico", de 20 de diciembre de 1905, en Revista de Derecho y Jurisprudencia 9 (Agosto de 1906), $2^{\text {a }}$ parte, sección $1^{\text {a }}$.

Figueroa, Luis S., Asignación y distribución de aguas terrestres (2a edición, Santiago, Universidad Gabriela Mistral, 1997).

García Moreno, Alejo (comp.), Colección de las instituciones politicas y jurídicas de los pueblos modernos. Segunda Serie: Estados modernos. República de Chile (Madrid, Revista de Legislación Universal, 1905), II.

Guzmán, Alberto - Ravera, Ernesto, Estudio de las Aguas (2a edición, Santiago, Ediciones Congreso, 1998).

Lastarria, José Victorino, Proyecto de Código Rural para la República de Chile: acompañado de un apéndice con notas ilustrativas (Santiago, Imprenta de la República, 1875).

Lira Ovalle, Samuel, El Derecho de Aguas ante la cátedra (Santiago, Universidad Católica de Chile, Facultad de Ciencias Jurídicas, Políticas y Sociales, 1956).

Lira Urquieta, Pedro - De la Maza, Lorenzo, Régimen legal de las aguas (Santiago, Editorial Nascimento, 1940).

Merino, Ernesto, Las comunidades de aguas, en Hederra, Ana - Vergara, Ciro, Comentarios al Código de Aguas (Santiago, Editorial Jurídica de Chile, 1960), I.

Оваndo, Iván M., La prenda especial de derechos de aguas: Antecedentes sobre derechos de aguas y contratos de garantía en perspectiva histórica (1855-1981), en Revista de Derecho de la Pontificia Universidad Católica de Valparaíso 26 (2005) 2.

ОваNDo, Iván, Los orígenes de la jurisdicción arbitral en el Derecho de aguas chileno, en Ius et Praxis 11 (2005) 2.

Seda, Mario, Las Juntas de Vigilancia en el Código de Aguas, en Hederra, Ana Vergara, Ciro, Comentarios al Código de Aguas (Santiago, Editorial Jurídica de Chile, 1960), II.

Sociedad del Canal de la Calera de Tango, Estatutos de la Sociedad del Canal de la Calera de Tango (Santiago, Imprenta y Encuadernacion Roma, 1895).

Sociedad del Canal de Maipo, Canal San Carlos: origenes e influencia en la ciudad de Santiago (Santiago, Max Huber, 1989).

Sociedad del Canal de Maipo, Direccion del Canal de Maipo 1827-1856 (Santiago, Imprenta Gutenberg, 1886).

Sociedad del Canal de Maipo, Recopilación ordenada de los Estatutos y de las Disposiciones Reglamentarias de la Sociedad del Canal de Maipo (Santiago, Imprenta Cervantes, 1899).

Somarriva, Manuel, Indivisión y Partición (4a edición, Santiago, Editorial Jurídica de Chile, 1987).

Stewart, Daniel, El Derecho de Aguas en Chile: Algunos aspectos de su historia y el caso del Valle de Illapel (Santiago, Editorial Jurídica de Chile, 1970).

Venegas, Fortunato, Legislacion Chilena sobre Aguas de Regadio (Santiago, Imprenta Gutenberg, 1887). 